\title{
El êthos discursivo de los antagonistas aristofánicos en las comedias Caballeros y Avispas
}

\author{
María Jimena SCHERE \\ Universidad de Buenos Aires \\ jimenaschere@hotmail.com
}

Recibido: $16-04-2012$

Aceptado: 20-12-2012

\section{RESUMEN}

La técnica del êthos, según Aristóteles, consiste en forjar una imagen positiva del orador, que lo hace digno de crédito y favorece el efecto persuasivo. En este trabajo nos proponemos analizar un uso particular de la técnica del êthos en las comedias Caballeros y Avispas de Aristófanes; se trata del uso paródico que suelen realizar los personajes negativos de la comedia aristofánica, esto es, los antagonistas de los héroes cómicos. Los discursos de Paflagonio-Cleón en Caballeros y de Filocleón en Avispas, adversarios de los héroes cómicos, se caracterizan por tener un efecto nocivo sobre la imagen de su enunciador: no logran exaltar la imagen de quien lo pronuncia, sino por el contrario demolerla bajo los efectos de la autodenuncia. Este empleo especial, paródico, de la técnica retórica del êthos logra socavar a los ojos del público la posición defendida por los personajes negativos de la comedia, como por ejemplo las ideas del líder contemporáneo Cleón. En definitiva, el êthos «negativo» tiene la ventaja de producir un efecto cómico y, a la vez, un efecto persuasivo degradante respecto del blanco al cual descalifica. Esta doble función hace que el recurso resulte tan eficaz para la comedia aristofánica, que tiene como objetivo central hacer reír a su público y, conjuntamente, persuadirlo de ciertas ideas políticas.

Palabras clave: êthos, imagen negativa, antagonistas, humor, persuasión.

\begin{abstract}
The technique of the êthos, Aristotle says, is to forge a positive image of the speaker, which makes it credible and favors the persuasive effect. In this work we propose to analyze a particular use of the technique of ethos in Aristophanes' Knights and Wasps; this is the parodic use often made by those negative characters in the aristophanic comedy, i.e. the antagonists of the comic heroes. The speeches of Paphlagon-Cleon in Knights and Philocleon in Wasps, adversaries of the comic heroes, are characterized by having a harmful effect on the image of his enunciator: these speeches don't exalt the image of the one who speaks, but on the contrary demolish it under the effects of the self-denounce. This particular parodic use of the technique of êthos undermine in the eyes of the public the position defended by the negative characters of the comedy, such as the ideas of the contemporary leader Cleon. The «negative» êthos has the advantage of producing a comic effect and, in turn, a persuasive effect degrading his target. This dual role makes the resource so effective for aristophanic comedy, which has as its central goal to make people laugh and, at the same time, persuade it about certain political ideas.
\end{abstract}

Keywords: êthos, negative image, antagonists, humor, persuasion. 


\section{INTRODUCCIÓN}

Los personajes de la comedia aristofánica suelen emplear múltiples técnicas persuasivas para sostener sus puntos de vista. Por ejemplo, Diceópolis, el héroe cómico de Acarnienses, hace un uso extendido de la retórica en sus discursos a favor de la paz entre Atenas y Esparta ${ }^{1}$. Del mismo modo, el héroe Bdelicleón aprovecha estos recursos en Avispas para argumentar en contra de los abusos de poder de los políticos y jueces atenienses. A propósito de este despliegue retórico por parte de los protagonistas aristofánicos, Murphy (1938) ha sostenido que el comediógrafo, a pesar de las críticas que esgrime contra el arte retórico, estaba familiarizado con sus técnicas ${ }^{2}$.

Dentro del repertorio clásico de recursos argumentativos, la construcción del êthos del orador constituye una de las estrategias fundamentales que permiten persuadir al receptor, de acuerdo con la visión de Aristóteles en su Retórica. La técnica del êthos opera cada vez que el orador forja en su discurso una imagen positiva de sí mismo que lo hace digno de crédito (áłı́́rı que tornan a los oradores dignos de confianza son el buen juicio ( $\varphi \rho o ́ v \eta \sigma ı \varsigma)$, la virtud

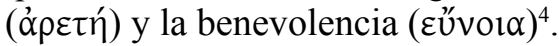

La estrategia retórica del êthos está claramente presente en algunas partes convencionales de la comedia aristofánica. Por ejemplo, en la parábasis de las obras el coro presenta una imagen laudatoria del enunciador-poeta ${ }^{5}$ al elogiar su función de consejero y de educador del pueblo. El êthos discursivo del enunciador-poeta, construido obra tras obra, se propone legitimar el lugar del comediógrafo como una palabra autorizada y confiable en el terreno de los asuntos públicos 6 . También los personajes favorecidos en cada pieza suelen elaborar un retrato positivo de sí mismos para ganar el crédito de los espectadores, como el mencionado caso de los héroes cómicos Diceópolis y Bdelicleón, que se presentan ante los ojos del público bajo la imagen de ciudadanos justos y honrados.

${ }^{1}$ Cf., por ejemplo, Ach. 497-556.

${ }^{2}$ Para demostrarlo, Murphy (1938) rastrea algunos recursos argumentativos de la retórica tradicional presentes en la comedia, como el uso de las partes convencionales del discurso en los parlamentos de los personajes, la utilización de conectores característicos, de tópoi retóricos, entre otros. Henderson (1990) también reconoce en la comedia la presencia de técnicas de persuasión idénticas a las utilizadas en el discurso político. Por su parte, Ober y Strauss (1990) destacan la interrelación entre el discurso público del teatro y el de la oratoria. Sobre la relación entre comedia aristofánica y retórica, cf. también Heath (1997), Hesk (2000) y Beta (2004).

${ }^{3}$ Rh. I. 8 1356a.

${ }^{4}$ Rh. II. 1 1378a. El problema del êthos ha sido abordado por una serie de estudiosos contemporáneos, provenientes del área del análisis del discurso, que han retomado y a la vez reformulado los conceptos aristotélicos, como Amossy (1999) y Maingueneau (1999) (2002).

${ }^{5}$ Los términos «enunciador» y «enunciatario» suelen referirse a una construcción de carácter discursivo. El enunciador tiene una identidad interna al discurso, que se diferencia del emisor o sujeto empírico, es decir, el locutor externo, que posee una identidad social (cf. Charaudeau y Maingueneau, [2002] 2005: 541-2). En el caso de la comedia aristofánica, el emisor es el autor o el productor de la obra y el enunciador es la identidad discursiva que se construye del autor en el propio discurso teatral.

${ }^{6}$ Sobre la construcción del êthos del enunciador-poeta en las parábasis, cf. Schere (2011). 
En este trabajo nos proponemos analizar un empleo particular de la técnica del êthos. Se trata del uso paródico que suelen realizar los personajes negativos de la comedia aristofánica, esto es, los antagonistas de los héroes cómicos. Los discursos de Paflagonio en Caballeros y de Filocleón en Avispas, adversarios de los héroes cómicos Morcillero y Bdelicleón respectivamente, se caracterizan por tener un efecto paródico negativo: no logran exaltar la imagen de quien lo pronuncia, sino por el contrario demolerla bajo los efectos de la autodenuncia. Este empleo especial, paródico y a la vez paradójico, de la estrategia del êthos consigue socavar la posición defendida por los personajes negativos de la comedia. En este sentido, según intentaremos demostrar, el comediógrafo apela de manera sistemática al recurso de construir un êthos «negativo» de los antagonistas, a fines de devaluar posiciones políticas adversas, como las ideas del líder contemporáneo Cleón, encarnado por el personaje de Paflagonio en Caballeros.

\section{LA FUNCIÓN PERSUASIVA DEL ÊTHOS NEGATIVO EN CABALLEROS}

La comedia Caballeros es la primera de las obras conservadas del comediógrafo que emplea de manera profusa el recurso de lo que llamaremos el êthos negativo, esto es, el uso paródico de la técnica del êthos. Caballeros desarrolla en escena el enfrentamiento entre Paflagonio-Cleón y su rival, el Morcillero, que le disputa la influencia sobre el pueblo votante. Cleón era por el momento de la representación de la obra, de acuerdo con el testimonio de Tucídides (III. 36, 6: 9), la figura dominante de la asamblea. En este contexto, Caballeros intenta devaluar la figura histórica del demagogo Cleón a través de una serie de estrategias discursivas.

Desde la primera aparición de Paflagonio, sus parlamentos socavan la imagen del propio enunciador-personaje en forma sistemática. Veamos su primera intervención frente a sus oponentes, los esclavos Nicias y Demóstenes?:

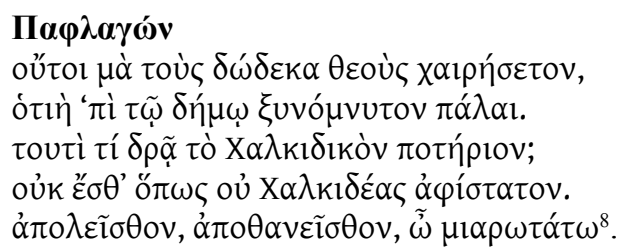

Paflagonio: ¡Por los doce dioses! Ciertamente no os alegraréis los dos de conspirar hace tiempo contra el pueblo.

¿Qué hace aquí esta copa calcídica?

${ }^{7}$ Según los manuscritos medievales, los dos esclavos que disputan contra Paflagonio representan a Nicias y Demóstenes. Nicias pertenecía al ala política moderada, era rival político de Cleón y se desempeñó como estratega durante el momento en que se llevó a cabo la campaña de Pilo (cf. Th. IV. 27, 29). El general Demóstenes, por su parte, fue el impulsor y el responsable del plan táctico de la campaña de Pilo. Sommerstein (1981: 144-5) acepta la identidad de los dos servidores. Sobre la identidad de los esclavos, cf. Dover (1959) y Henderson (2003) (2006: 222).

${ }^{8}$ Utilizamos la edición de Wilson (2007). Las traducciones son propias. 
Sin duda que incitáis a la defección a los calcidences.

Seréis destruidos, moriréis, canallas.

(vv. 235-239)

La primera acusación de Paflagonio-Cleón contra sus adversarios carece de toda prueba: la intención de mover a defección a los calcidenses por la mera posesión de un objeto. El carácter caprichoso e infundado de esta imputación se propone poner de manifiesto la tendencia de Cleón a difamar a sus rivales ${ }^{9}$, visión del personaje que prevalece en toda la obra ${ }^{10}$. La deducción absurda que va de la posesión del objeto a la acusación de incitar a defección es un recurso cómico que se dirige contra el propio personaje que la pronuncia. Se trata de una parodia de entimema fundada en una premisa inaceptable: la posesión de un objeto de procedencia extranjera implica la existencia de una relación conspirativa entre los extranjeros y el poseedor del objeto. Esta forma de razonamiento retórico, que en la oratoria política sirve para justificar el punto de vista del enunciador, produce en su versión paródica un efecto inverso: desautorizar la postura del enunciador-personaje. En otras palabras, la argumentación de Paflagonio para atacar a sus adversarios en escena no logra socavar la imagen de su blanco de ataque, sino que se vuelve contra el propio personaje que la pronuncia. La acusación de Paflagonio aparece minada por su carácter exagerado e inverosímil y, por ende, construye un êthos negativo del enunciador-personaje, que lo torna digno de desconfianza, en lugar de volverlo confiable.

El segundo parlamento de Paflagonio-Cleón se vale nuevamente del mismo recurso. Ante el ataque físico y verbal del coro de caballeros, que se suma a la embestida contra el líder, Paflagonio pide ayuda a los jueces atenienses de una manera tal que desautoriza sus propias palabras:

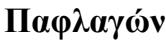

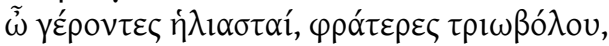

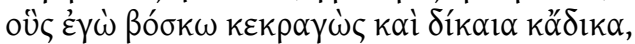

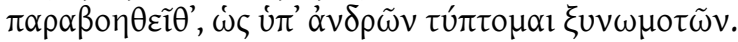

\section{Xopó $\varsigma$}

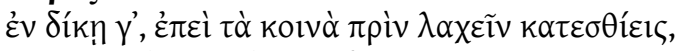

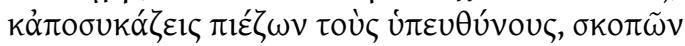

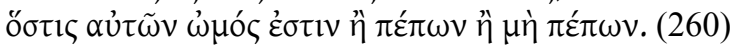

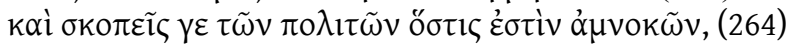

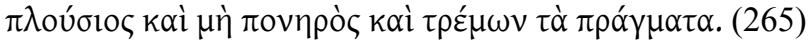

Paflagonio: Viejos heliastas, cofrades del trióbolo, a quienes alimento, gritando cosas justas e injustas, venid en mi ayuda porque soy golpeado por hombres conjurados.

Coro $^{11}$ : Y con justicia, porque devoras los fondos comunes, antes de tocarte

[en suerte tu parte,

${ }^{9}$ Neil (1966: 37), Sommerstein (1981: 155).

${ }^{10}$ Véanse, por ejemplo, vv. 7, 257, 452, 476-9, 628, 862.

${ }^{11}$ Wilson (2007) atribuye los versos 258 ss. a Demóstenes. Sin embargo, consideramos que el parlamento pertenece al coro, quien protagoniza en este pasaje el ataque contra Paflagonio (cf. Sommerstein, 1981; Neil, 1966). 
y presionas oprimiendo a los obligados a rendir cuentas como higos, viendo cuál de estos está verde o maduro o no maduro aún; y miras cuál de los ciudadanos tiene mente de cordero, es rico y no malvado y temeroso de los asuntos públicos.

(vv. 255-265)

Los jueces atenienses, a quienes invoca Paflagonio en primer lugar, aparecen como firmes partidarios del líder en virtud del aumento de su salario, que se ridiculiza mediante la expresión «Cofrades del trióbolo»" ${ }^{12}$. La fratría era una asociación religiosa de familias que creían compartir un ancestro común ${ }^{13}$. La comicidad de esta imagen aflora de la asociación inesperada entre un término religioso y dignificado, por un lado, y un término mundano y de clara carga negativa en la obra como el salario de tres óbolos ${ }^{14}$. En Caballeros no solo se presenta a Cleón como un difamador compulsivo de sus rivales políticos, sino también como un demagogo obsecuente, que intenta seducir al pueblo con magros beneficios al tiempo que él se queda con las mayores ganancias. La referencia al aumento del salario a tres óbolos, propiciado efectivamente por el líder Cleón, se propone denunciar esta imagen de obsecuencia mediante la metáfora ridiculizante de la fratría. Como en el caso anterior, los parlamentos de Paflagonio no ridiculizan ni atacan a sus oponentes, sino al propio Cleón; es decir que hasta el momento todas sus intervenciones no involucran argumentos de autodefensa, sino de autodenuncia, ya sea de sus maniobras políticas de difamación, ya sea de sus estrategias de seducción hacia el dêmos.

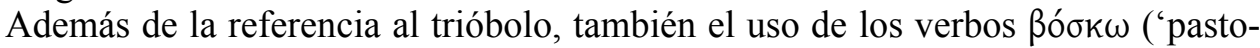

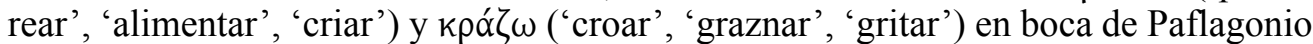
tienen un efecto degradante sobre el propio enunciador-personaje (v. 256). El primer verbo $(\beta o ́ \sigma K \omega)$ ubica a los jueces en posición de animales de pastoreo y presenta a Cleón como un líder nocivo para su pueblo ${ }^{15}$; el segundo verbo $(\kappa \rho \alpha ́ \zeta \omega)$ construye un auto-retrato animalizado, salvaje y agresivo, del propio Cleón. La animalización, recurso cómico corriente en Aristófanes, tiene el efecto de devaluar la imagen del personaje por su estilo oratorio violento ${ }^{16}$. Por último, la descripción que hace Paflagonio sobre el contenido de su discurso («gritando cosas justas e injustas», v. 256), no solo lo deja en ridículo a los ojos del público por lo insólito de su afirmación, sino que a la vez destruye su propia imagen en el plano moral. En definitiva, sus parlamentos presentan la visión de un líder político carente de buen juicio, deshonesto y malvado, valores

${ }^{12}$ El salario diario de los jueces era inicialmente de dos óbolos, pero había sido aumentado a tres por iniciativa de Cleón (Sommerstein, 1981: 147).

${ }^{13}$ Sommerstein (1981: 156).

${ }^{14}$ Orfanos (2006: 37) observa que en la fratría ficticia de Cleón sus miembros no tienen en común otra cosa que el interés económico.

${ }^{15}$ Neil (1966: 40) señala que el uso de estos términos demuestra el arrogante dominio de Cleón sobre los jueces.

${ }^{16}$ El retrato del estilo oratorio de Paflagonio-Cleón coincide con el que describe Tucídides, quien lo presenta como «el más violento de los ciudadanos (III. 36, 6: 8)». También La Constitución de Atenas, atribuida a Aristóteles, sostiene que Cleón fue el primero en gritar en la asamblea $(28,3)$. Al respecto, cf. MacDowell (1995: 82). 
contrarios a los que promueve la retórica Aristotélica para generar una imagen confia-

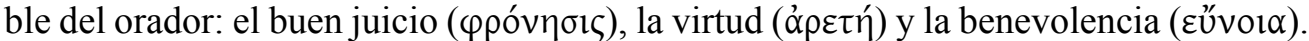

Pero la figura de Cleón en su primera actuación en escena no solo es degradada a través de sus propias intervenciones, sino también por medio de los ataques de sus oponentes. Por ejemplo, en los versos 258-263 recién citados, los caballeros acusan a Cleón de robar fondos públicos, imputación permanente en toda la obra. Asimismo, el coro se burla del líder a través de la imagen de los higos: «Y presionas oprimiendo a los obligados a rendir cuentas como higos, viendo cuál de estos está verde o maduro, o no maduro aún» (vv. 259-60). La imagen de los higos busca producir una asociación

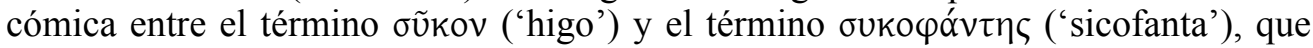
literalmente significa 'revelador de higos' ${ }^{17}$. Mediante este juego, Cleón es retratado como un sicofanta que acusa a los magistrados salientes, obligados a rendir cuentas al término de sus funciones.

En suma, en el primer enfrentamiento entre Cleón y sus enemigos, los argumentos que esgrimen los oponentes de Paflagonio satirizan y muestran las faltas de PaflagonioCleón y, al mismo tiempo, las propias intervenciones de Paflagonio, en lugar de atacar y ridiculizar a sus adversarios, lo dejan en ridículo a él mismo y dañan su figura a los ojos del espectador ateniense. Esto significa que el ataque contra Paflagonio opera por doble vía: (1) a través de los parlamentos del propio personaje; (2) a través de sus adversarios, multiplicidad que potencia la fuerza persuasiva de la embestida contra el líder.

El coro de caballeros inaugura, a partir del verso 277, una competencia entre los dos rivales a los fines de demostrar cuál de los dos supera al otro en desvergüenza $\left(\alpha{ }^{\prime} v \alpha^{\prime} \delta \varepsilon l \alpha\right)^{18}$. Esta competencia avanza también mediante la técnica del êthos negativo: los dos contrincantes rivalizan en espejo para demostrar quién es peor. Las breves intervenciones de cada uno minan su propia imagen, sobre todo en el plano moral. Veamos un breve ejemplo:

\section{$\Pi \alpha \varphi \lambda \alpha \gamma \omega ́ v$}

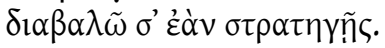

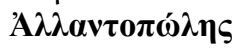

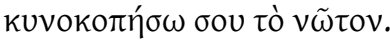

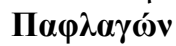

$\pi \varepsilon p 1 \varepsilon \lambda \tilde{\omega} \sigma^{\prime} \alpha \lambda \alpha \zeta o v \varepsilon i ́ \alpha ı \zeta$.

А $\lambda \lambda \alpha v \tau 0 \pi \omega \dot{\lambda} \eta \varsigma$

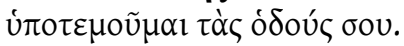

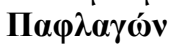

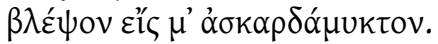

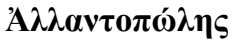

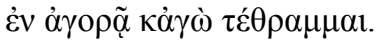

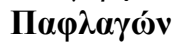

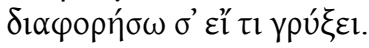

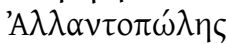

${ }^{17}$ Sommerstein (1981: 157).

${ }^{18}$ Thiercy (1986: 239) observa que la inversión de valores domina la pieza: todo lo que es considerado como virtud deviene vicio, y lo que es considerado vicio se transforma en virtud. 


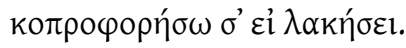

$\Pi \alpha \varphi \lambda \alpha \gamma \omega \dot{\omega} v$

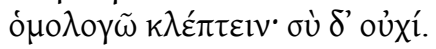

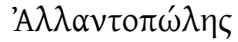

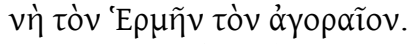

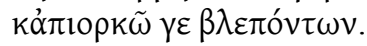

Paflagonio: Te difamaré, si eres estratega.

Morcillero: Te golpearé como a un perro el lomo.

Paflagonio: Te cercaré con imposturas.

Morcillero: Te cortaré el camino.

Paflagonio: Mírame a mí, que no parpadeo.

Morcillero: Yo también me he criado en el Ágora.

Paflagonio: Te haré pedazos, si refunfuñas algo.

Morcillero: Te cubriré con mierda, si gritas.

Paflagonio: Confieso que robo y tú no.

Morcillero: Sí, ¡por Hermes del Ágora!

$\mathrm{Y}$ juro en falso cuando me ven.

(vv. 288-298)

En el marco de la competencia, Paflagonio saca a relucir su tendencia a la difamación (v. 288), a la impostura (v. 290), la violencia (v. 299) y al robo (v. 296). Toda la escena presenta a los contrincantes como dos fanfarrones que se vanaglorian de su falta de escrúpulos. Paflagonio, por ejemplo, a fines de superar a su adversario, se ufana de su aptitud para robar, jactancia que tiene el efecto de socavar cómicamente su imagen pública.

La autodenuncia está presente hasta el final de la pieza, también en el último agón que se desarrolla en presencia de Demos, personificación del pueblo votante. En el verso 746, Paflagonio-Cleón le solicita a Demos que reúna una asamblea para decidir cuál de los dos rivales se muestra más benévolo hacia él. A partir del verso 763 comienza, entonces, una parodia de antilogía frente al dêmos en la cual los dos contrincantes despliegan su argumentación. El primer alegato de Paflagonio en su propia defensa se refiere a los beneficios económicos que le ha brindado presuntamente al dêmos:

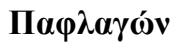

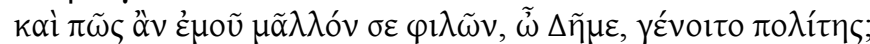

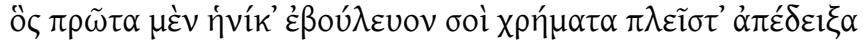

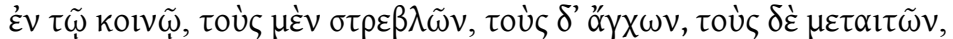

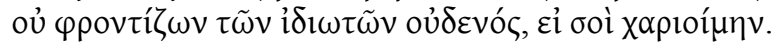

Paflagonio: ¿Y cómo, Demos, podría haber un ciudadano que te ame más que yo? Primero, cuando era consejero, te asigné mucho dinero en los fondos públicos, atormentando a unos, estrangulando a los otros, reclamando a otros, sin preocuparme por ningún particular, con tal de agradarte a ti.

(vv. 773-776) 
Paflagonio destaca, por un lado, los beneficios que le ha otorgado al pueblo, pero al mismo tiempo se delata a sí mismo mostrando los métodos ilegales que ha utilizado a fines de obtener fondos públicos. Una vez más el personaje se defiende a sí mismo frente a Demos degradando, a mismo tiempo, su êthos discursivo.

En conclusión, a partir del análisis de algunos ejemplos extraídos a lo largo de toda la pieza, podemos afirmar que Caballeros implementa como una de sus estrategias centrales para desautorizar al líder la técnica del êthos negativo o de la autodenuncia. El personaje de Paflagonio se propone atacar a sus oponentes o defender su acción pública, pero no hace otra cosa que socavar su imagen y conseguir el efecto contrario del que pretende.

La técnica de la autodenuncia tiene dos efectos a la vez: en primer lugar un efecto cómico y, en segundo orden, un efecto persuasivo sobre el público. El efecto cómico está dado por la ruptura de la expectativa que genera. La ruptura de expectativas es una de las causas que algunos filósofos como Aristóteles, Kant y Schopenhauer han presentado como origen de la risa. Kant (1790), por ejemplo, sostiene que la risa es producto de una esperanza defraudada: «En todo lo destinado a provocar una risa viva, una carcajada, tiene que haber un contrasentido (...). La risa es una afección procedente de trasformarse repentinamente en nada una expectación tensa» ${ }^{19}$. En la misma línea de la teoría kantiana, Schopenhauer (1819) explica el fenómeno de la risa como un efecto de la percepción de incongruencias entre la abstracción y la intuición ${ }^{20}$.

El êthos negativo que construye Paflagonio quiebra el marco de expectativas de cualquier discurso serio: el receptor de un discurso persuasivo espera que el orador elabore una imagen positiva de sí. Por el contrario, Paflagonio ataca y se defiende minando en todo momento la construcción de su êthos en términos aristotélicos. La risa se produce, entonces, por un efecto de inversión, que subvierte el autorretrato acostumbrado del orador confiable. A este quiebre de lo esperado, atribuimos la eficacia cómica del recurso.

Por otro lado, además del efecto cómico, fundamental en el marco genérico de la comedia, hemos observado que el êthos negativo produce un efecto secundario persuasivo: degrada la imagen de Paflagonio-Cleón al presentarlo como un sujeto corrupto, inmoral e incapaz de defenderse mediante su argumentación. En este sentido, el recurso de la autodenuncia resulta sumamente operativo para el género de la comedia antigua en tanto aúna la generación de un efecto cómico y a la vez persuasivo, dos finalidades centrales de la obra de Aristófanes.

\section{LA FUNCIÓN PERSUASIVA DEL ÊTHOS NEGATIVO EN AVISPAS}

La comedia Avispas pone en escena el enfrentamiento entre el viejo juez Filocleón, adicto a la actividad judicial e impiadoso con los imputados, y su hijo Bdelicleón,

${ }^{19}$ Kant (2005: 185). En Retórica (III. 1412a 25-28) encontramos un antecedente de la teoría kantiana del humor como ruptura de expectativas. Sobre la teoría aristotélica de la risa, cf. Gil Fernández (1998: 311).

${ }^{20}$ Schopenhauer (2008: 117) sostiene que «la causa de lo risible está siempre en la subsunción o inclusión paradójica - y, por lo tanto, inesperada - de una cosa en un concepto que no le corresponde; y la risa indica que de repente se advierte la incongruencia entre dicho supuesto y la cosa pensada, es decir, entre la abstracción y la intuición». 
quien intenta alejarlo definitivamente de las cortes y retenerlo en su hogar. Nos detendremos en el análisis del agón principal entre el héroe Bdelicleón y su antagonista Filocleón, que se centra en la discusión sobre qué sector - jueces o políticos del ala radical - detenta el poder real en Atenas. Filocleón defiende la postura de que los jueces gozan de las mayores atribuciones, mientras que su hijo considera que no son más que esclavos y títeres de los demagogos. Los versos 512-514, pronunciados por Bdelicleón, preparan el comienzo del agón formal ${ }^{21}$ (vv. 526-724) entre padre e hijo:

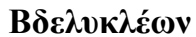

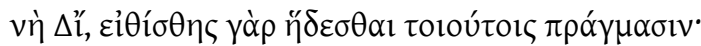

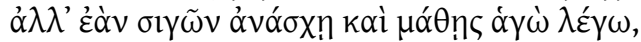

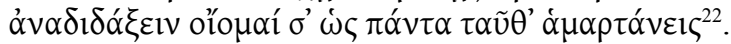

Bdelicleón: ¡Por Zeus! Te acostumbraste a encontrar gusto en acciones de este tipo. Pero si soportas callarte y entiendes lo que digo, creo que te enseñaré que te equivocas en todo esto.

(vv. 512-4)

Bdelicleón emplea el verbo ỏv $\alpha \delta 1 \delta \alpha ́ \sigma \kappa \omega$ ('enseñar' o 'enseñar mejor') para definir el tipo de función que se dispone a asumir en el agón formal; este verbo lo emparienta en sí mismo con la figura del poeta-educador, delineada en las parábasis ${ }^{23}$, y lo ubica ya desde el preludio del agón en una posición favorecida. Bdelicleón construye un êthos positivo de sí mismo, que lo contrapone a la práctica de la autodenuncia, presente - según veremos - en todo el discurso de Filocleón.

En la apertura de su argumentación, Filocleón se propone demostrar que un juez goza de inmenso poder:

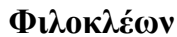

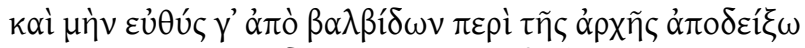

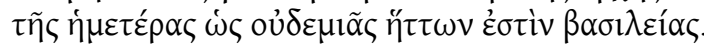

Filocleón: Directamente y desde el comienzo demostraré que el poder nuestro no es inferior a ninguna realeza.

El comienzo del parlamento de Filocleón anuncia, mediante el uso del verbo

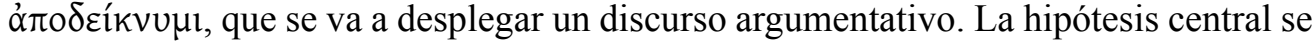

${ }^{21}$ Geltzer (1960: 19-20) ubica un primer agón epirremático en los versos 334-402, que presentan el diálogo entre Filocleón y el coro en sus intentos de liberar al anciano; el segundo agón epirremático se desarrolla en los versos 526-724 y despliega el debate central entre la postura de Filocleón y la de su hijo. Reckford (1987: 522 n. 17), por su parte, prefiere considerar solo los versos 526-727 como el agón de la comedia.

${ }^{22}$ Utilizamos la edición de Wilson (2007).

${ }^{23}$ La visión del poeta como educador de su pueblo se hace explícita en la parábasis de Acarnienses mediante el uso del verbo $\delta_{1} \delta \alpha ́ \sigma K \omega$ en el verso 656 y 658 : «[El poeta] dice que os enseñará muchas cosas buenas, de modo que seáis felices, / sin adularos, sin prometeros salarios, sin engañaros, / sin ser malvado, sin regaros con elogios, sino enseñándoos lo que es mejor» (vv. 656-8). 
presenta directamente en el verso 249 sin mayores proemios ${ }^{24}$ : el poder de los jueces no es inferior a ninguna realeza. El anciano se propone de este modo refutar las afirmaciones de su hijo, quien ha sostenido que él es en realidad un esclavo (v. 517). Si bien los argumentos de Filocleón demostrarán que ese poder existe — aunque no sea ilimitado como Filocleón pretende_- tienen la contrapartida de destruir su éthos discursivo. Cada uno de los ejemplos que el juez aporta para demostrar su ópxท́ manifiestan no solo que ese poder es efectivo, sino que el enunciador abusa del mismo a cada momento. Por lo tanto, el alegato de Filocleón resulta una argumentación deficiente y paródica de cualquier discurso serio en la medida en que echa por tierra su propia imagen, aspecto que ningún orador descuidaría; en otras palabras, el discurso de Filocleón es en sí mismo un alegato en contra del propio orador. El personaje presenta como hechos naturales, o incluso positivos, acciones que dañan definitivamente su figura a los ojos del receptor. Se trata exactamente de la misma técnica que se aplica en Caballeros, especialmente, durante la competencia en torno a la desvergüenza: los dos competidores, Paflagonio y el Morcillero, destacan como hechos positivos acciones moralmente condenables.

En cada una de las cinco partes de su discurso, el anciano describe situaciones concretas que intentan ejemplificar el poder de los jueces ${ }^{25}$; es decir que dentro de los recursos retóricos tradicionales se apela, fundamentalmente, al $\pi \alpha \rho \alpha ́ \delta \varepsilon l \gamma \mu \alpha^{26}$; pero sus ejemplos, a diferencia de lo que ocurriría en cualquier argumentación seria, tienen la contrapartida de mostrar una imagen condenable del enunciador-personaje. En la primera parte de su alegato, para demostrar su poder, Filocleón describe la actitud suplicante de los imputados antes del juicio:

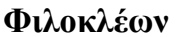

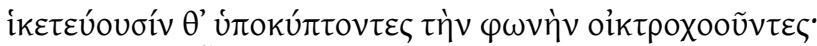

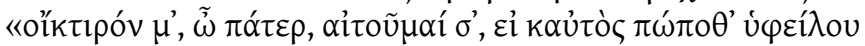

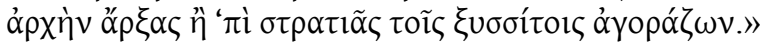

Filocleón: (...) Me suplican haciendo reverencias, con voz lastimera: «Ten compasión de mí, padre, te lo suplico, si tú mismo alguna vez robaste cuando ejercías una magistratura o cuando comprabas provisiones para tus

[compañeros en el ejército». (vv. 555-7)

La súplica del acusado sugiere la falta de integridad del juez y retoma su imagen de ladrón ${ }^{27}$, coincidente por cierto con el retrato de Paflagonio. Este primer ejemplo del poderío de Filocleón lo deja cómicamente en evidencia como un hombre deshonesto.

${ }^{24}$ Murphy (1938: 81) sostiene que este parlamento utiliza la forma más simple de proemio: la próthesis.

${ }^{25}$ MacDowell (1971: 206) ha destacado también que el discurso de Filocleón no presenta generalizaciones, sino ejemplos vivamente descriptos. Asimismo, McGlew (2004: 16) reafirma que el discurso de Filocleón es «concreto y personal».

${ }^{26}$ Aristóteles (Rh. I. 2 1356b) presenta las distintas formas de razonamiento retórico y entre ellas incluye el ejemplo.

${ }^{27}$ En el verso 354, el coro menciona también un antiguo robo de Filocleón. Esta imagen de ladrón se retoma, especialmente, al final de la obra con el rapto de la flautista. Konstan (1985: 33 n. 21) ha contabilizado diecinueve referencias al robo en la obra. 
La argumentación avanza en orden cronológico: la segunda parte narra la actitud de Filocleón una vez que ingresa en los tribunales:

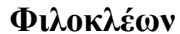

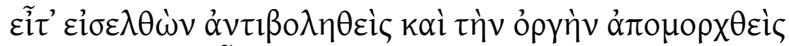

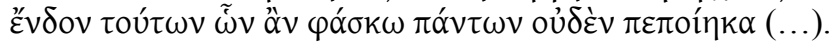

Filocleón: Entonces, una vez que entro, después de que me hayan suplicado

[y de calmar mi cólera, adentro no cumplo ninguna de todas las promesas que he hecho.

(vV. 560-1)

La argumentación prosigue coherentemente en la línea de la autodenuncia: Bdelicleón deja a la vista una vez más su deshonestidad, por ser incapaz de cumplir una promesa, y se jacta de su actitud.

A partir del verso 578, se desarrolla la tercera parte de la argumentación del viejo juez. El recurso empleado vuelve a ser un ejemplo que intenta poner de manifiesto la supremacía de los jueces: Filocleón menciona su ventaja de poder ver los genitales de los jóvenes cuando son sometidos a examen con la finalidad de comprobar si tienen la edad suficiente para ser inscriptos en el registro de ciudadanos. Entre otros beneficios, Filocleón destaca además que los jueces tienen la posibilidad de entregar a una hija heredera a la persona que más les convenga, violando la voluntad del difunto padre (vv. 583-86). Por último, Filocleón se jacta de no tener que rendir cuentas, a diferencia de todas las otras magistraturas (v. 587) ${ }^{28}$. Nuevamente, el anciano celebra una serie de acciones reprobables a los ojos del espectador ateniense, que dejan al descubierto sus abusos de poder y las posibles fallas del sistema.

En el resto de su argumentación (vv. 590 ss.), Filocleón destaca que los políticos los respetan y adulan, y hasta el mismo Cleón les espanta las moscas (vv. 596-7). Finalmente, describe las atenciones que recibe, por interés, de su familia y servidores cuando llega a su casa en virtud del salario que cobra por su actividad de juez (vv. 605 ss.). Esta secuencia sugiere, según observa Dover, que el anciano mantiene contactos incestuosos con su hija (vv. 607-9 $)^{29}$. Al cierre de su discurso de defensa y en la cumbre de su megalomanía, Filocleón sostiene que su poder no es inferior al de Zeus (v. 619) y que todos los ricos y encumbrados le temen (vv. 626-9), incluso su hijo (v. 629).

La autodenuncia es, en suma, la estrategia de persuasión cómica dominante en todo el discurso de Filocleón y está presente también en el resto de la obra ${ }^{30}$. Al igual que en la comedia Caballeros, el antagonista es atacado por doble vía: la denuncia llega por boca de sus oponentes, el héroe Bdelicleón en este caso, y también por boca del propio

\footnotetext{
${ }^{28}$ Sommerstein (1996: 193) señala que si bien ser juez no era técnicamente una magistratura, podía ser informalmente descripta como tal.

${ }^{29}$ Dover (1972: 127).

${ }^{30} \mathrm{La}$ autodenuncia se implementa, por ejemplo, en la presentación del personaje cuando Filocleón se describe a sí mismo como «humo de higuera» (v. 145), en una alusión a su actividad de juez injusto cercana a la del sicofanta. También en su diálogo con el coro Filocleón habla en contra de sí mismo. Por ejemplo, en el verso 340 el juez se queja de su hijo ante el coro porque no le permite juzgar ni «ni hacer

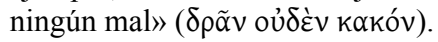


blanco que habla en contra de sí mismo. El efecto resultante de esta doble ofensiva es la potenciación de la devaluación del blanco a los ojos del público.

\section{CONCLUSIONES}

La técnica de êthos negativo se forja en la comedia Caballeros, que hace de ella un uso profuso, y se implementa nuevamente en la comedia Avispas. En las dos obras el recurso asume funciones semejantes: socavar la imagen del antagonista del héroe y blanco central de la pieza (Paflagonio y Filocleón). Hemos observado que la autodenuncia tiene la ventaja de producir un efecto cómico por la ruptura de expectativas que genera y, a la vez, un efecto persuasivo degradante respecto del blanco al cual descalifica. Esta doble función hace que el recurso resulte tan eficaz para la comedia aristofánica, que tiene como objetivo central hacer reír a su público y, conjuntamente, persuadirlo de ciertas ideas políticas. En la comedia Caballeros, la autodenuncia colabora con la estrategia argumentativa de afectar el liderazgo del Cleón histórico; en el caso de Avispas, devalua la imagen de los jueces atenienses y sus abusos de poder.

La técnica del êthos positivo es una estrategia argumentativa seria compartida por la oratoria no ficcional (i.e. discursos deliberativos, forenses y epidícticos, en términos de Aristóteles) y la oratoria ficcional, presente en los discursos de muchos héroes aristofánicos como Diceópolis o Bdelicleón. En cambio, la técnica del êthos negativo es de carácter estrictamente cómico, por la consecuente ruptura de la expectativa que genera. Por otra parte, la autodenuncia solo puede existir en el plano de la ficción en tanto involucra la construcción de un personaje que se condena a sí mismo. Podemos afirmar entonces que la implementación de este recurso constituye un eficaz hallazgo del comediógrafo, que le permite lograr un efecto humorístico y a la vez persuasivo en el marco de la ficción, a pesar de que algunos autores han desestimado la posibilidad de que la comedia pueda tener intenciones argumentativas.

En contra de nuestra visión, algunos autores como Heath (1997) han sostenido que la comedia aristofánica se apropia de tópicos de la retórica política, pero que hace de ellos un uso paródico que le resta fuerza persuasiva a la comedia ${ }^{31}$. A nuestro entender, el uso paródico de técnicas argumentativas como la construcción del êthos del orador, no le quita potencia argumentativa a la pieza. Por el contrario, hemos intentado demostrar que el êthos negativo y paródico de los antagonistas aristofánicos puede devaluar de manera real y efectiva a los ojos del público ateniense el discurso de estos personajes. El humor paródico logra que el ataque contra el blanco se vuelva más eficaz en tanto la risa genera complicidad ${ }^{32}$ entre el público-enunciatario y el

${ }^{31}$ Cf. Halliwell (1984: 19) y recientemente Rosen (2007: 21-22).

32 Bergson [1900] (1991: 14) ha sido quizás el primero en señalar la relación entre humor y complicidad: «nuestra risa es siempre la risa de un grupo (...). Por muy espontánea que se crea, siempre oculta un prejuicio de asociación y hasta de complicidad con otros rientes efectivos o imaginarios». Por su parte, Freud [1905] (2006: 97) observa que el chiste tendencioso es capaz de generar complicidad entre el emisor y el receptor a causa de la ganancia de placer que provoca en este último. A la luz de estos dos enfoques, podemos sostener que los recursos cómicos son capaces de provocar un efecto positivo de empatía entre emisor y receptor. 
enunciador-autor. Al tiempo que produce esta complicidad entre emisor y receptor, la autodenuncia vehiculiza ideas negativas sobre el blanco, a través de la ficción y la risa, de manera más subrepticia e indirecta, y quizás por eso más efectiva, que la oratoria no ficcional.

\section{BIBLIOGRAFÍA}

Amossy, Ruth (ed.) (1999), Images de soi dans le discours, Lausanne-Paris: Delachaux et Niestlé. Bergson, Henri [1900] (19914), La risa. Ensayo sobre el significado de lo cómico, Buenos Aires: Losada (trad. española A. H. Raggio).

Beta, Simone (2004), Il linguaggio nelle commedie di Aristofane. Parola positiva e parola negativa nella comedia antica (Suppl. n. 21/22 al Bollettino dei Classici), Roma: Accademia Nazionale dei Lincei.

Charaudeau, Patrick y Maingueneau, Dominique [2002] (2005), Diccionario de análisis del discurso, Buenos Aires - Madrid: Amorrortu editores (trad. española I. Agoff).

Dover, Kenneth J. (1959), «Aristophanes, Knights 11-20», CR 9: 196-199.

Dover, Kenneth J. (1972), Aristophanic Comedy, Berkely - Los Ángeles: University of California Press.

Freud, Sigmund [1905] (2006² 7. a reimpr.), El chiste y su relación con lo inconsciente, Buenos Aires: Amorrortu Editores (trad. española J. L. Etcheverry).

Gil FERnÁNDEZ, Luis (1998), «La risa y lo cómico en el pensamiento antiguo», en J. A. López Férez (ed.), La comedia griega y su influencia en la literatura española, Madrid: 307-343.

Gelzer, Thomas (1960), Der epirrhematische Agon bei Aristophanes. Untersuchungen zur Struktur der attischen alten Komödie (Zetemata 23), München: C. H. Beck.

Halliwell, Stephen (1984), "Aristophanic Satire», The Yearbook of English Studies 14: 6-20.

Heath, Malcolm (1997), «Aristophanes and the Discourse of Politics», en G. W. Dobrov (ed.), The City as Comedy, Chapel Hill - London: 230-249.

Hesk, Jon (2000), Deception and Democracy in Classical Athens, Cambridge: Cambridge University Press.

Henderson, Jeffrey (1990), «The Demos and the Comic Competition», en J. J. Winkler y F. I. Zeitlin (eds.), Nothing to do with Dionysos? Athenian Drama in its Social Context, Princeton - New Jersey: 271-313.

Henderson, Jeffrey (ed., trad.) [1998] (2006 1. a reimpr.), Aristophanes. Acharnians. Knights, vol. 1, Cambridge - Massachussets: Harvard University Press.

Henderson, Jeffrey (2003), "When an identity was expected: the slaves in Aristophanes' Knights», en G. W. Bakewell y J. P. Sickinger (eds.), Gestures. Essays in Ancient History, Literature, and Philosophy Presented to Alan L. Boegehold. On the occasion of his retirement and his seventy-fifth birthday, Oxford: 63-300.

Kant, Immanuel [1790] (2005), Crítica del juicio, Buenos Aires: Losada (trad. española J. R. Armengol).

Konstan, David (1985), «The Politics of Aristophanes’ Wasps», TAPhA 115: 27-46.

MacDowell, Douglas M. (ed., com.) (1971), Aristophanes. Wasps, Oxford: Oxford Clarendon Press. 
MacDowell, Douglas M. (1995), Aristophanes and Athens. An Introduction to the Plays, Oxford: Oxford University Press.

Maingueneau, Dominique (1999), «Ethos, scénographie, incorporation», en R. Amossy (dir.), Images de soi dans le discours. La construction de l'ethos, Lausanne - Paris: 75-100.

Maingueneau, Dominique (2002), «Problèmes d'ethos», Pratiques 113/114: 55-67.

McGlew, James F. (2004), «'Speak on my Behalf': Persuasion and Purification in Aristophanes' Wasps», Arethusa 37: 11-36.

Murphy, Charles T. (1938), "Aristophanes and the Art of Rhetoric», HSPh 49: 69-133.

NeIL, Robert A. (ed., com.) [1901] (1966), The Knigths of Aristophanes, Hildesheim: Georg Olms.

Ober, Josiah y Strauss, Barry (1990), «Drama, Political Rhetoric, and the Discourse of Athenian Democracy», en J. J. Winkler y F. I. Zeitlin (eds.), Nothing to do with Dionysos? Athenian Drama in its Social Context, Princeton - New Jersey: 237-270.

Orfanos, Charalampos (2006), Les sauvageons d'Athènes ou la didactique du rire chez Aristophane, Paris: Les Belles Lettres.

Reckford, Kenneth J. (1987), Aristophanes Old-an-New Comedy, Chapel Hill - London: University of North Carolina Press.

Rosen, Ralph M. (2007) Making Mockery. The Poetics of Ancient Satire, Oxford: Oxford University Press.

SCHERE, M. Jimena (2011), «La construcción del éthos discursivo en la parábasis de Avispas», Anales de Filología Clásica 21: 139-160.

SCHOPENHAUER, Arthur [1819] (2008), El mundo como voluntad y representación, Buenos Aires: Losada (trad. española E. Ovejero y Maury).

Sommerstein, Alan. H. (ed., trad., com.) (1981), The comedies of Aristophanes. Knights, vol. 2, Warminster: Aris \& Phillips.

Sommerstein, Alan. H. (ed., trad., com.) [1983] (1996 reimpr. corregida) Aristophanes. Wasps, vol. 4, Warminster: Aris \& Phillips.

THIERCy, Pascal (1986), Aristophane: fiction et dramaturgie, Paris: Les Belles Lettres.

Tovar, Antonio (ed., trad.) (1953), Aristóteles. Retórica, Madrid: Instituto de Estudios Políticos.

Wilson, Nigel Guy (ed.) (2007), Aristophanis Fabulae, t. 1, Oxford: Oxford University Press. 